\title{
Rapid Communication: Use of pressure mat gait analysis in measuring pain following normal parturition in dairy cows
}

\author{
Michael D. Kleinhenz, ${ }^{*,+\odot}$ Patrick J. Gorden,* Michael Burchard,* Joshua A. Ydstie,* and \\ Johann F. Coetzee $* \hbar, 1$ \\ *Department of Veterinary Diagnostic and Production Animal Medicine, Iowa State University, Ames, IA \\ 50011; 'Department of Clinical Science, Kansas State University, Manhattan, KS 66506; and Department of \\ Anatomy and Physiology, Kansas State University, Manhattan, KS 66506
}

\begin{abstract}
Research investigating the pain of normal parturition is lacking as there are few objective methods for measuring pain. The objective of this research was to describe the gait of cows following eutocia using pressure mat gait analysis; and if meloxicam alters the gait of cows. Twenty Holstein cows within $26 \mathrm{~h}$ of unassisted calving were enrolled into the study. Treatment groups included: 1) postpartum cows administered meloxicam (MEL; $n=10$ ); and 2) postpartum cows administered placebo (PLBO; $n=10$ ). Meloxicam was administered by oral bolus at $1 \mathrm{mg} /$ $\mathrm{kg}$ within $26 \mathrm{~h}$ of calving. Placebo cows were given an oral bolus of dry whey powder within $26 \mathrm{~h}$ of calving. A commercially available floor mat-based pressure/force measurement system was used to compare ambulation between treatment groups. Cows were walked across the mat before treatment administration, and 2, 4, 6, 8, 12, 24, 48, and $72 \mathrm{~h}$ posttreatment. The percent of total force, percent
\end{abstract}

total contact pressure, and percent total impulse of the rear limbs were calculated. Outcome measures were statistically analyzed using repeated measures, with the cow serving as the experimental unit. Cows in the MEL group placed 48.9\% (95\% CI: $47.4 \%$ to $50.5 \%$ ) of total force on the rear limbs compared to $46.3 \%$ (95\% CI: $44.7 \%$ to $47.9 \%)$ in PLBO cows $(P=0.02)$. Total impulse on their rear limbs for the MEL cows was $50.5 \%$ (95\% CI: $48.6 \%$ to $52.4 \%$ ) compared to $46.7 \%$ (95\% CI: $44.8 \%$ to $48.7 \%$ ) for the PLBO cows $(P=0.01)$. No differences in contact pressure of the rear limbs were observed $(P=0.27)$. The PLBO cows had a longer gait $101.3 \mathrm{~cm}(95 \% \mathrm{CI}$ : $95.9 \%$ to $106.6 \mathrm{~cm})$ vs. $90.8 \mathrm{~cm}(95 \% \mathrm{CI}: 85.4 \%$ to $96.1 \mathrm{~cm})(P=0.03)$. These findings show meloxicam-treated cows have altered weight distribution to the rear limbs as measured by pressure mat gait analysis, suggesting meloxicam may effectively treat postpartum pain.

Key words: animal welfare, dairy cattle, gait, nonsteroidal anti-inflammatory drug; post-parturient

(C) The Author(s) 2018. Published by Oxford University Press on behalf of the American Society of Animal Science. All rights reserved. For permissions, please e-mail: journals.permissions@oup.com.

J. Anim. Sci. 2019.97:846-850 doi: $10.1093 /$ jas/sky450

\section{INTRODUCTION}

There has been an increase in research focused on ways to improve dairy cow health and well-being in the immediate postpartum period.

${ }^{1}$ Corresponding author: jcoetzee@vet.k-state.edu

Received November 6, 2018.

Accepted November 20, 2018.
Nonsteroidal anti-inflammatory drugs (NSAID) have been investigated for their pharmacological effects in the reduction of inflammation associated with calving (Laven et al., 2012). Practitioners regard calving to be a painful event, but studies investigating the pain associated with normal partition are deficient (Remnant et al., 2017).

Meloxicam is an NSAID that acts as a cyclooxygenase (COX) inhibitor. Injectable meloxicam is 
approved in the European Union and Canada as an adjunctive therapy to treat acute respiratory infection, diarrhea, pain relief associated with dehorning, and acute mastitis (EMEA, 2009). Recently, pressure mat gait analysis was used as a validated method of pain assessment for the Food and Drug Administration (FDA) approval of transdermal flunixin meglumine for the control of pain associated with foot rot (US FDA, 2017). The objectives of this research were 1) to investigate the use of pressure mat gait analysis to describe the gait of cows in the immediate postpartum period and 2) determine the effects of meloxicam on gait in cows administered oral meloxicam in the immediate postpartum period. Our hypothesis was that meloxicam administration in the immediate postpartum period would be effective at treating postpartum pain as evidenced by altered gait of post-parturient dairy cows measured by contact force, contact pressure, step impulse, and gait length.

\section{MATERIALS AND METHODS}

This study was approved by the Institutional Animal Care and Use Committee at Iowa State University (Protocol 4-16-8243-B).

\section{Animals and Study Design}

The methods used for treatment allocation and enrollment have been previously published by Gorden et al. (2018).

The study population consisted of 20 Holstein cows enrolled within $26 \mathrm{~h}$ of calving. To be eligible for enrollment, cows had to be free of lameness (score $\leq 2$ out of 5 ) when assessed using a visual lameness scoring system described by Sprecher et al. (1997); have no history of receiving meloxicam in the past $30 \mathrm{~d}$; and had a calving ease score $<2$. The latter enrollment criterion was to eliminate excessive pain associated with dystocia. Postpartum cows were randomly assigned into their treatment group on the day of calving using the RAND function in a spreadsheet program (Microsoft Excel, Richmond, WA). Postpartum cows were assigned to receive either meloxicam (MEL; $n=10$; Meloxicam tablets $15 \mathrm{mg}$, Cadila Healthcare Ltd, India) at $1 \mathrm{mg} / \mathrm{kg}$ by oral bolus or a placebo bolus containing whey protein powder $(\mathrm{PLBO} ; n=10$; Body Fortress Super Advance whey protein, Healthwatchers, Inc., Bohemia, NY). All treatments were administered as an oral bolus with the treatment article within a gelatin bolus (size \#07, Torpac Inc., Fairfield, NJ). Treatment occurred immediately after the midday (noon) milking.
On the day of calving, cows were evaluated for inclusion criteria. If inclusion criteria were met, the cow was weighed for treatment dosing and placed onto the research study. All evaluations, body weight determinations, and time 0 (T0) collections were completed prior to the 12:00 p.m. milking on the day of enrollment.

Cows were group housed in a free-stall barn bedded with recycled manure solids. Cows were feed a total mixed ration with ad libitum access to water. Cows were milked by study personnel using farm protocols at 4:00 a.m., 12:00 p.m., and 8:00 p.m.

\section{Gait Analysis}

Gait analysis was completed using a commercially available floor mat-based system (MatScan, Tekscan, Inc., South Boston, MA). Data were collected prior to treatment (T0) and 2, 4, 6, 8, 12, 24,48 , and $72 \mathrm{~h}$ after treatment. Video synchronization was used to ensure consistent gait between and within cows for each time point. Research software (HUGEMAT Research 5.83, Tekscan, Inc., South Boston, MA) was used to determine force, contact pressure, and impulse (area under the force vs. time curve) using methods previously described (Kotschwar et al., 2009; Schulz et al., 2011; Coetzee et al., 2014). The percent of total force, percent total contact pressure, and percent total impulse of the rear limbs were determined using the equation:

$$
\begin{aligned}
\% \text { Force Rear }= & {[(\text { Left Rear Force }+ \text { Right Rear Force })} \\
& \div(\text { Left Rear Force }+ \text { Right Rear Force } \\
& + \text { Left Front Force }+ \text { Right Front Force })] * 100
\end{aligned}
$$

\section{Statistical Analysis}

Contact force was used to determine the number of cows needed per treatment group. The study was designed to have a statistical power of 0.80 assuming an effect size in differences of $122 \mathrm{~kg}$ force with a SE of 36.8 and as reported by Coetzee et al. (2014). A sample size of 10 animals per treatment group was determined.

Statistical analysis was performed using commercially available computer software (JMP Pro 13, SAS Institute, Cary, NC). Statistical analysis was completed using repeated measures, with the cow serving as the experimental unit. Fixed effects were treatment (MEL/PLBO), time, and treatment by time interaction. Interaction between groups was completed using Tukey's HSD. Statistical significance was established when $P \leq 0.05$. 


\section{RESULTS}

The mean body weight \pm SD of cows enrolled were as follows: MEL $699 \pm 117 \mathrm{~kg}$; and PLBO $686 \pm 46 \mathrm{~kg}$.

Results from pressure mat analysis are summarized in Table 1. The mean step force of the rear limbs was $393.4 \mathrm{~kg}$ (95\% CI: $327.2 \%$ to $459.5 \mathrm{~kg}$ ) for the MEL cows and $331.3 \mathrm{~kg}(95 \% \mathrm{CI}: 265.2 \%$ to $397.5 \mathrm{~kg})$ for the PLBO cows $(P=0.15)$. There was evidence of a treatment effect on the $\%$ of total force by the rear limbs applied to the mat $(P=0.02)$ with the MEL cows applying $48.9 \%$ (95\% CI: $47.4 \%$ to $50.5 \%$ ) of the force on their rear limbs. The PLBO group placed $46.3 \%$ (95\% CI: $44.7 \%$ to $47.9 \%$ ) of force on their rear limbs. The MEL cows had a mean rear pressure of $7.1 \mathrm{~kg} / \mathrm{cm}^{2}(95 \% \mathrm{CI}: 5.8 \%$ to $8.5 \mathrm{~kg} / \mathrm{cm}^{2}$ ) compared to $6.2 \mathrm{~kg} / \mathrm{cm}^{2}$ (95\% CI: $4.8 \%$ to $\left.7.6 \mathrm{~kg} / \mathrm{cm}^{2}\right)$ for the PLBO group $(P=0.27)$.

Cows in the MEL group had 50.5\% $(95 \% \mathrm{CI}$ : $48.6 \%$ to $52.4 \%$ ) of the total impulse on their rear limbs compared to $46.7 \%$ (95\% CI: $44.8 \%$ to $48.7 \%$ ) for the PLBO group $(P=0.01)$. No treatment by time interaction was appreciated $(P=0.53)$. The PLBO had a longer gait [101.3 cm $(95 \% \mathrm{CI}: 95.9$ to $106.6 \mathrm{~cm})]$ compared to the MEL $[90.8 \mathrm{~cm}(95 \% \mathrm{CI}$ : 85.4 to $96.1 \mathrm{~cm})](P=0.03$; Fig. 1$)$.

\section{DISCUSSION}

There is a paucity of literature on the pain associated with normal calving events. The percent of total force by the rear limbs was determined to account for differences in cow body weight and distribution of weight by each limb. These findings show that cows treated with meloxicam following calving distribute more weight to the rear limbs compared to placebo cows. When gait analysis was used following surgical castration, a change in the force applied by the front limbs compared to rear limbs was found with castrated calves placing more force on their front limbs (Kleinhenz et al., 2018). This change was attributed to the calf shifting its weight to the front limbs, away from the castration site following the procedure, as the change in weight distribution was not seen in uncastrated controls.

The pressure mat system utilized to determine outcome variables in this study has been used in castration and lameness studies (Kotschwar et al., 2009; Schulz et al., 2011; Coetzee et al., 2014; Kleinhenz et al., 2018). Additionally, the technology used in the current study is similar to that used for the label claim for pain control by transdermal flunixin meglumine (US FDA, 2017). In the pivotal approval study, flunixin-treated calves applied more force on the affected foot while walking across the mat after $8 \mathrm{~h}$ compared to placebo control. Thus, pressure mat gait analysis is considered a validated pain measure in cattle.

Cows in the MEL group had shorter gait lengths compared to PLBO group. An explanation of this observation may be that meloxicam lowered the pain associated with udder edema associated with calving. Meloxicam has been shown to improve pain sensitivity of the mammary gland of cows

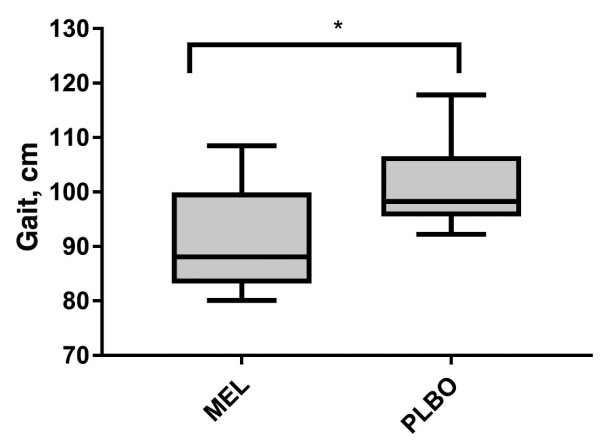

Figure 1. Mean gait $(\mathrm{cm})$ for Holstein cows given meloxicam $(1.1 \mathrm{mg} / \mathrm{kg}$ ) within $26 \mathrm{~h}$ of parturition (MEL) or placebo within $26 \mathrm{~h}$ of parturition (PLBO). $* P \leq 0.05$.

Table 1. Summary of pressure mat outcomes (LS mean \pm SEM) for Holstein cows given meloxicam $(1.1 \mathrm{mg} /$ $\mathrm{kg}$ ) within $26 \mathrm{~h}$ of parturition (MEL) or placebo within $26 \mathrm{~h}$ of parturition (PLBO)

\begin{tabular}{|c|c|c|c|c|c|}
\hline \multirow[b]{2}{*}{ Parameter } & \multicolumn{2}{|c|}{$\mathrm{LS}_{\text {mean }}{ }^{ \pm} \pm \mathrm{SEM}$} & \multicolumn{3}{|c|}{$P$-value } \\
\hline & MEL & PLBO & Treatment & Time & Treatment $\times$ time \\
\hline Force rear limbs (kg) & $393.4 \pm 31.4$ & $331.3 \pm 31.4$ & 0.15 & 0.95 & 0.25 \\
\hline$\%$ Force on rear limbs & $48.9^{a} \pm 0.7$ & $46.3^{b} \pm 0.7$ & 0.02 & 0.08 & 0.81 \\
\hline Contact pressure rear limbs $\left(\mathrm{kg} / \mathrm{cm}^{2}\right)$ & $7.1 \pm 0.6$ & $6.2 \pm 0.6$ & 0.27 & 0.97 & 0.23 \\
\hline$\%$ Contact pressure on rear limbs & $49.5 \pm 0.1$ & $49.8 \pm 0.1$ & 0.17 & 0.16 & 0.65 \\
\hline Impulse rear limbs $(\mathrm{kg} \times \mathrm{s})$ & $252.7 \pm 19.6$ & $213.0 \pm 19.6$ & 0.11 & 0.39 & 0.12 \\
\hline$\%$ Impulse on rear limbs & $50.5^{\mathrm{a}} \pm 0.9$ & $46.7^{b} \pm 0.9$ & 0.01 & 0.15 & 0.52 \\
\hline Gait $(\mathrm{cm})$ & $90.9^{\mathrm{a}} \pm 2.5$ & $101.4^{\mathrm{b}} \pm 2.5$ & 0.03 & 0.78 & 0.31 \\
\hline
\end{tabular}

${ }^{\mathrm{a}, \mathrm{b}}$ Superscripts with different letters are significant $(P \leq 0.05)$.

${ }^{1}$ Least square means. 
with induced endotoxic mastitis (Fitzpatrick et al., 2013). Furthermore, cows with induced mastitis have been shown to avoid weight shifting (Chapinal et al., 2013). The authors speculate it is in an effort to decrease friction rubbing between the leg and inflamed udder. The longer observed gait observed in the PLBO cows may be due to exaggerated steps to minimize leg-udder friction and contact.

Meloxicam and sodium salicylate have been shown to significantly increase milk production over the entire lactation when given following calving (Carpenter et al., 2016). These data make the administration of meloxicam an enticing way to increase production with a single intervention. Neither meloxicam nor salicylate are approved by the US FDA for use in lactating dairy cows and thus constitute an extra-label drug use (ELDU). However, ELDU would be restricted to relieving pain and suffering under the Animal Medicinal Drug Use Clarification Act (AMDUCA) and not to enhancement of production (US FDA, 1996).

Studies investigating meloxicam administration on cow behavior in the postpartum period have yielded equivocal results (Newby et al., 2013; Mainau et al., 2014). Timing of meloxicam administration was similar to the current study, but route of administration and dose was different. The study presented here used oral administration at $1 \mathrm{mg} / \mathrm{kg}$ compared to $0.5 \mathrm{mg} / \mathrm{kg}$ by subcutaneous injection in the previously referenced studies. In cattle, oral meloxicam given at $1.0 \mathrm{mg} / \mathrm{kg}$ has $100 \%$ bioavailability, and reaches a maximum concentration of $3.1 \mu \mathrm{g} / \mathrm{mL}$ (Coetzee et al., 2009).

The data presented here are the first to characterize the gait of cows following eutocia using floor-based pressure mat analysis technology. The changes in weight distribution when measured by pressure mat analysis show meloxicam may be beneficial to cows immediately following calving. Further research is needed to elicit details on pain associated with normal parturition and the role NSAID therapy may have in cows during the immediate postpartum period.

\section{ACKNOWLEDGMENTS}

The authors would like to thank Erica Hellmich, Cassandra Rice, Curtis Kornthanke, Adlai Schuler, Dan Breuer, and Caitlyn Dierks for their assistance with sample collection and processing. This project was funded by Iowa State University's College of Veterinary Medicine and the Iowa Livestock Health Advisory Council.

\section{LITERATURE CITED}

Carpenter, A. J., C. M. Ylioja, C. F. Vargas, L. K. Mamedova, L. G. Mendonca, J. F. Coetzee, L. C. Hollis, R. Gehring, and B. J. Bradford. 2016. Hot topic: early postpartum treatment of commercial dairy cows with nonsteroidal antiinflammatory drugs increases whole-lactation milk yield. J. Dairy Sci. 99:672-679. doi:10.3168/jds.2015-10048

Chapinal, N., C. E. Fitzpatrick, K. E. Leslie, and S. A. Wagner. 2013. Short communication: experimentally induced mastitis reduces weight shifting between the rear legs while standing in dairy cows. J. Dairy Sci. 96:3039-3043. doi:10.3168/jds.2012-6397

Coetzee, J. F., B. KuKanich, R. Mosher, and P. S. Allen. 2009. Pharmacokinetics of intravenous and oral meloxicam in ruminant calves. Vet. Ther. 10:E1-E8.

Coetzee, J. F., R. A. Mosher, D. E. Anderson, B. Robert, L. E. Kohake, R. Gehring, B. J. White, B. KuKanich, and C. Wang. 2014. Impact of oral meloxicam administered alone or in combination with gabapentin on experimentally induced lameness in beef calves. J. Anim. Sci. 92:816829. doi:10.2527/jas.2013-6999

European Agency for the Evaluation of Medicinal Products (EMEA). 2009. Web site: Committee for Veterinary Medicinal Products. Meloxicam. Maximum residue limit (MRL) summary report (3). http://www.emea.europa. eu/docs/en_GB/document_library/Maximum_Residue Limits_-_Report/2009/11/WC500014949.pdf (Accessed 18 June 2018).

Fitzpatrick, C. E., N. Chapinal, C. S. Petersson-Wolfe, T. J. DeVries, D. F. Kelton, T. F. Duffield, and K. E. Leslie. 2013. The effect of meloxicam on pain sensitivity, rumination time, and clinical signs in dairy cows with endotoxin-induced clinical mastitis. J. Dairy Sci. 96:2847-2856. doi:10.3168/jds.2012-5855

Gorden, P. J., M. Burchard, J. A. Ydstie, M. D. Kleinhenz, L. W. Wulf, S. J. Rajewski, C. Wang, R. Gehring, J. P. Mochel, and J. F. Coetzee. 2018. Comparison of milk and plasma pharmacokinetics of meloxicam in postpartum versus mid-lactation Holstein cows. J. Vet. Pharmacol. Ther. 41:463-468. doi:10.1111/jvp. 12488

Kleinhenz, M. D., N. K. Van Engen, J. S. Smith, P. J. Gorden, J. Ji, C. Wang, S. C. B. Perkins, and J. F. Coetzee. 2018. The impact of transdermal flunixin meglumine on biomarkers of pain in calves when administered at the time of surgical castration without local anesthesia. Livest. Sci. 212:1-6. doi:10.1016/j.livsci.2018.03.016

Kotschwar, J. L., J. F. Coetzee, D. E. Anderson, R. Gehring, B. KuKanich, and M. D. Apley. 2009. Analgesic efficacy of sodium salicylate in an amphotericin B-induced bovine synovitis-arthritis model. J. Dairy Sci. 92:3731-3743. doi:10.3168/jds.2009-2058

Laven, R., P. Chambers, and K. Stafford. 2012. Using non-steroidal anti-inflammatory drugs around calving: maximizing comfort, productivity and fertility. Vet. J. 192:8-12. doi:10.1016/j.tvj1.2011.10.023

Mainau, E., A. Cuevas, J. L. Ruiz-De-La-Torre, E. Abbeloos, and X. Manteca. 2014. Effect of meloxicam administration after calving on milk production, acute phase proteins, and behavior in dairy cows. J. Vet. Behav. 9:357-363. doi:10.1016/j.jveb.2014.07.007

Newby, N. C., D. L. Pearl, S. J. LeBlanc, K. E. Leslie, M. A. G. von Keyserlingk, and T. F. Duffield. 2013. Effects of meloxicam on milk production, behavior, and feed 
intake in dairy cows following assisted calving. J. Dairy Sci. 96:3682-3688. doi:10.3168/jds.2012-6214

Remnant, J. G., A. Tremlett, J. N. Huxley, and C. D. Hudson. 2017. Clinician attitudes to pain and use of analgesia in cattle: where are we 10 years on? Vet Rec. 181:400. doi:10.1136/vr.104428

Schulz, K. L., D. E. Anderson, J. F. Coetzee, B. J. White, and M. D. Miesner. 2011. Effect of flunixin meglumine on the amelioration of lameness in dairy steers with amphotericin B-induced transient synovitis-arthritis. Am. J. Vet. Res. 72:1431-1438. doi:10.2460/ajvr.72.11.1431

Sprecher, D. J., D. E. Hostetler, and J. B. Kaneene. 1997. A lameness scoring system that uses posture and gait to predict dairy cattle reproductive performance. Theriogenology 47:1179-1187. doi:10.1016/ s0093-691x(97)00098-8

US Food and Drug Administration (US FDA). (1996). Extralabel drug use in animals. 21CFR530 Fed. Regist. 61:57732-57746. https://www.accessdata.fda.gov/scripts/ cdrh/cfdocs/cfcfr/CFRSearch.cfm?fr=530.20 (Accessed 20 September 2018).

US Food and Drug Administration (US FDA). (2017). Freedom of information summary original new animal drug application Banamine Transdermal. US FDA CVM. https:// animaldrugsatfda.fda.gov/adafda/app/search/public/document/downloadFoi/1944 (Accessed 20 September 2018). 